
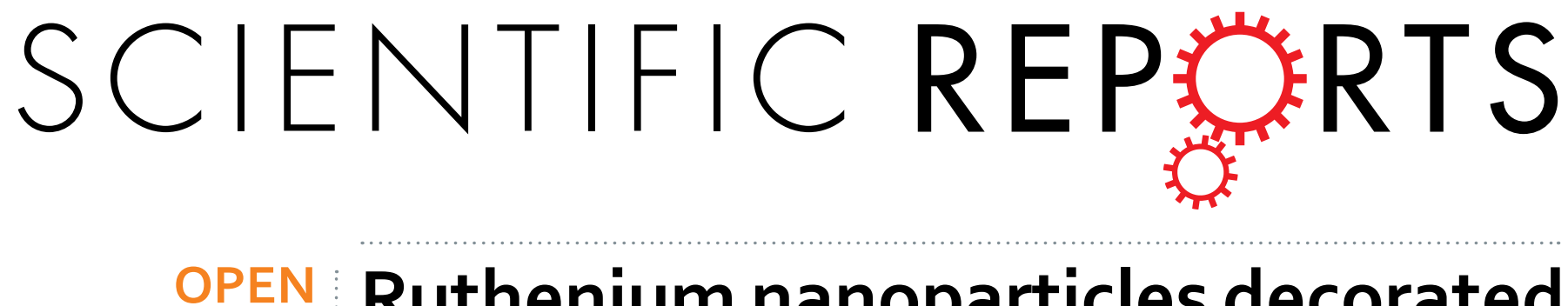

\title{
Ruthenium nanoparticles decorated curl-like porous carbons for high performance supercapacitors
}

Received: 24 September 2015

Accepted: 18 December 2015

Published: 28 January 2016

\author{
Bih-Show Lou ${ }^{1}$, Pitchaimani Veerakumar ${ }^{2}$, Shen-Ming $\mathrm{Chen}^{3}$, Vediyappan Veeramani ${ }^{3}$, \\ Rajesh Madhu ${ }^{3}$ \& Shang-Bin Liu ${ }^{2,4}$
}

The synthesis of highly dispersed and stable ruthenium nanoparticles (RuNPs; ca. 2-3 nm) on porous activated carbons derived from Moringa Oleifera fruit shells (MOC) is reported and were exploited for supercapacitor applications. The Ru/MOC composites so fabricated using the biowaste carbon source and ruthenium acetylacetonate as the co-feeding metal precursors were activated at elevated temperatures $\left(600-900^{\circ} \mathrm{C}\right)$ in the presence of $\mathrm{ZnCl}_{2}$ as the pore generating and chemical activating agent. The as-prepared $\mathrm{MOC}$ carbonized at $900^{\circ} \mathrm{C}$ was found to possess a high specific surface area $\left(2522 \mathrm{~m}^{2} \mathrm{~g}^{-1}\right)$ and co-existing micro- and mesoporosities. Upon incorporating RuNPs, the Ru/ MOC nanocomposites loaded with modest amount of metallic Ru (1.0-1.5 wt\%) exhibit remarkable electrochemical and capacitive properties, achiving a maximum capacitance of $291 \mathrm{~F} \mathrm{~g}^{-1}$ at a current density of $1 \mathrm{~A} \mathrm{~g}^{-1}$ in $1.0 \mathrm{M} \mathrm{H}_{2} \mathrm{SO}_{4}$ electrolyte. These highly stable and durable Ru/MOC electrodes, which can be facily fabricated by the eco-friendly and cost-effective route, should have great potentials for practical applications in energy storage, biosensing, and catalysis.

Porous activated carbon (PAC)-related materials offer great advantages for practical applications ${ }^{1,2}$, such as adsorbents, energy storage, catalyst supports, and electrodes for fuel cells $\mathrm{s}^{3-12}$. Moreover, owing to the intrinsic properties, such as high surface area, diversified morphology, good electrical conductivity, and tailorable porosity, PACs are also favorable materials as supports for metal nanoparticles (NPs) or metal oxides, and have been widely applied as biomolecule sensors ${ }^{13-15}$, biomedical engineering materials ${ }^{16}$, toxic molecules/heavy metal detectors ${ }^{17,18}$, and supercapacitors ${ }^{18-33}$. In terms of the latter, aside from the widely studied carbon materials such as graphene ${ }^{34-38}$, carbon nanotubes ${ }^{37-40}$, and ordered mesoporous carbons $s^{41-44}$, PACs are easy to prepare, eco-friendly, and cost-effective; they may be prepared from renewable biomass precursors through facile carbonization and activation routes, for examples, from tree barks or leaves ${ }^{18,20-24}$, plants ${ }^{25,26}$, fruits ${ }^{27,28}$, grain or seed shells ${ }^{29-32,45-51}$, lignin ${ }^{52,53}$, food derivatives ${ }^{54}$, marine products ${ }^{33}$, and so on. Typically, the synthesis of PACs from biomass feedstock invokes a chemical activation method in which activating agents such as $\mathrm{ZnCl}_{2}, \mathrm{KOH}$, $\mathrm{NaOH}$, or $\mathrm{H}_{3} \mathrm{PO}_{4}$ are commonly introduced along with the biomass precursor ${ }^{2,14,15,20,32}$. Upon completion of a subsequent carbonization treatment, the substrate was then washed with concentrated $\mathrm{HCl}$ to obtain the PAC as the final product ${ }^{53,54}$.

We report herein the synthesis of stable, highly dispersed ruthenium nanoparticles (RuNPs) on PACs derived from Moringa Oleifera fruit shells. Moringa Oleifera is a fast-growing, deciduous tree also known as the "drumstick tree", mostly cultivated in Asian countries such as India, Philippines, and is also commonly seen in Africa, South America, the Caribbean and other Oceania countries ${ }^{55,56}$. Compare to other biomass feedstock, Moringa Oleifera, which belongs to the family of Moringaceae, is not only abundant in nature but also known to produe highly nutritious fruit ${ }^{57,58}$ that have medicinal ${ }^{59-61}$, and other applications $s^{62}$. Moreover, the Moringa Oleifera also contains cellulose, hemicellulose, and lignin that are desirable as precursors for fabrication of PACs with wormhole-like microstructures ${ }^{62-67}$ preferable as supports for electochemical and energy storage applicaions. By graphitizing the biowaste carbon precursor, namely Moringa Oleifera fruit shells along with $\mathrm{ZnCl}_{2}$ as activating

${ }^{1}$ Chemistry Division, Center for General Education, Chang Gung University, Taoyuan 33302, Taiwan. ${ }^{2}$ Institute of Atomic and Molecular Sciences, Academia Sinica, Taipei 10617, Taiwan. ${ }^{3}$ Department of Chemical Engineering and Biotechnology, National Taipei University of Technology, Taipei 10608, Taiwan. ${ }^{4}$ Department of Chemistry, National Taiwan Normal University, Taipei 11677, Taiwan. Correspondence and requests for materials should be addressed to B.S.L. (email: blou@mail.cgu.edu.tw) or S.M.C. (email: smchen78@ms15.hinet.net) or S.B.L. (email: sbliu@sinica. edu.tw) 


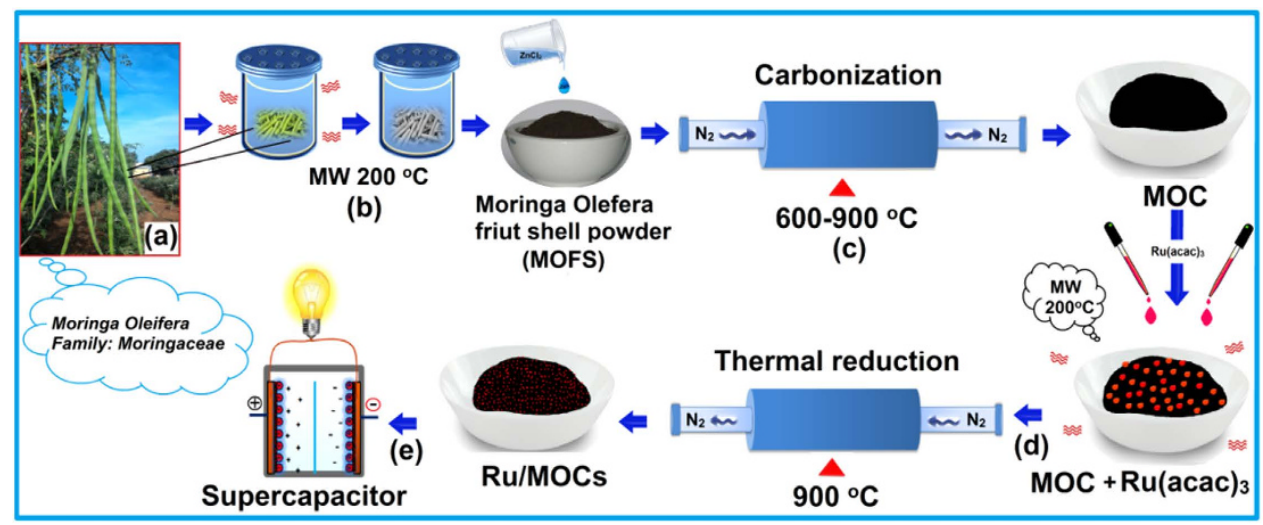

Figure 1. Illustration of the synthesis route for Ru/MOC nanocomposites. (a) Moringa Oleifera fruit shells; (b) thermal irradiation by microwave (MW); (c) activation and carbonization treatments; (d) addition of $\mathrm{Ru}(\mathrm{acac})_{3}$ followed by MW irradiation and thermal reduction at $900^{\circ} \mathrm{C}$; (e) $\mathrm{Ru} / \mathrm{MOC}$ nanocomposite electrode for supercapacitor application.

agent under $\mathrm{N}_{2}$ atmosphere at elevated temperatures, the PAC (hereafter termed as Moringa Oleifera carbons; MOC- $\left.\mathrm{T}_{\mathrm{c}}\right)$ so fabricated at different carbonization temperatures $\left(\mathrm{T}_{\mathrm{c}}=600-900^{\circ} \mathrm{C}\right)$ was further washed with $\mathrm{HCl}$ to remove the $\mathrm{Zn}^{2+}$ species. Subsequently, the as-synthesized MOC-900 was mixed with the metal precursor (i.e., ruthenium(III) acetylacetonate; $\mathrm{Ru}(\mathrm{acac})_{3}$ ) in ethanol solution followed by a thermal reduction treatment to disperse RuNPs onto the carbon support. It is noteworthy that, here, the $\mathrm{Ru}(\mathrm{acac})_{3}$ serves as the metal precursor as well as a secondary carbon source, which warrants not only simultaneous reduction of $\mathrm{Ru}^{\mathrm{III}}$ to $\mathrm{Ru}^{0}$ but also a high dispersion of RuNPs on the $\mathrm{MOC}^{7-12}$. As illustrated in Fig. 1, after a thermal reduction treatment at $900{ }^{\circ} \mathrm{C}$, the $\mathrm{Ru}_{x}$ /MOC-900 nanocomposites so fabricated with vaired Ru loadings ( $x=1.0$ and $1.5 \mathrm{wt} \%$ ) were found to exhibit excellent electrochemical properties desirable for electrochemical applications. To the best of our knowledge, this represents the first report to exploit Moringa oleifera fruit shells as the primary carbon source to fabricate PAC materials for such applications. As will be shown latter that the Ru/MOC nanocomposites prepared by this innovated facile and cost-effective route are indeed suitable as high-performance electrode materials for high-power supercapacitors.

\section{Results and Discussion}

Figure 2a shows the XRD patterns of the as-prepared MOC and Ru/MOC samples. For the MOC- $\mathrm{T}_{\mathrm{c}}$ samples prepared at different temperatures $\left(\mathrm{T}_{\mathrm{c}}=600-900^{\circ} \mathrm{C}\right)$, two broad peaks at $2 \theta=22.2$ and $43.4^{\circ}$ respectively corresponding to the (002) and (100) diffractions of amorphous graphitic carbon ${ }^{68}$ were observed. On the other hand, for the $\mathrm{Ru}_{x} / \mathrm{MOC}-900$ composites reduced at $900^{\circ} \mathrm{C}$ with different metal loading $(x=1.0$ and $1.5 \mathrm{wt} \%)$, additional sharp diffraction peaks at $2 \theta=38.3,42.2,44.0,58.3,69.4$, and $78.4^{\circ}$ were evident, which may be assigned to the (100), (002), (101), (102), (110), and (103) diffraction planes of hexagonal close-packed (hcp) Ru metal (JCPDS-ICDD card No. 06-0663) ${ }^{69}$. The Raman spectra of the MOC and Ru/OMC samples exhibited two main peaks located at 1363 and $1585 \mathrm{~cm}^{-1}$ (Fig. 2b), which may be attributed to vibration bands of carbons in disordered graphite ( $\mathrm{D}$ band) and the $\mathrm{E}_{2} \mathrm{~g}$ mode of the graphite ( $\mathrm{G}$ band), which is related to vibrations of $\mathrm{sp}^{2}$ carbon structure in two-dimensional (2D) hexagonal lattice $\mathrm{e}^{70}$. Moreover, for MOC carbonized at elevated temperatures $\left(\mathrm{T}_{\mathrm{c}} \geq 800^{\circ} \mathrm{C}\right)$, an additional vibrational peak corresponding to the overtone of the $\mathrm{D}$ band (i.e., the $2 \mathrm{D}$ band) at $2712 \mathrm{~cm}^{-1}$ was also observed ${ }^{71}$. Accordingly, the $\mathrm{G}$ to $\mathrm{D}$ band intensity ratio $\left(I_{\mathrm{G}} / I_{\mathrm{D}}\right)$ is normally used to assess the crystalline structure of the graphitic carbons, as depicted in Table 1 . That an $I_{\mathrm{G}} / I_{\mathrm{D}}$ ratio of 1.21 was observed for the MOC-900 and Ru/MOC-900, indicating a high degree of graphitization for the PAC supports.

Results obtained from $\mathrm{N}_{2}$ adsorption/desorption isotherms $(77 \mathrm{~K})$ showed that all MOC-based samples exhibit H1-type isotherms (see Fig. 2c; cf. IUPAC classification). The presence of a weak hysteresis loop at $P / P_{0}$ of $c a .0 .4$ together with the notable increase in $\mathrm{N}_{2}$ uptade at low relative pressures reveal the coexistence of micro- and mesoporosities in these carbon substrates ${ }^{72}$. Accordingly, the specific surface areas and pore volumes responsible for the micro- and mesoporosities may be derived, as depicted in Table 1. Further calculations by density functional theory (DFT) indicate that these MOC materials have an average mesopore size of ca. $4.0 \mathrm{~nm}$ (see Supporting Information, Fig. S1). Based on the above results, it is clear that the MOC-900, which possesses the highest BET surface area $\left(S_{\text {tot }}=2522 \mathrm{~m}^{2} \mathrm{~g}^{-1}\right)$ and total pore volume $\left(V_{\text {tot }}=1.78 \mathrm{~cm}^{3} \mathrm{~g}^{-1}\right)$, exhibits superior textural properties and $I_{\mathrm{G}} / I_{\mathrm{D}}$ value. Compared to its counterparts carbonized at relatively lower temperautres, it is indicative that the MOC-900 substrate is more suitable for application as electrode material owing to the anticipated higher electrical conductivity and porosity, which are favorable for electron transport and ion diffusion. Upon loading RuNPs onto the MOC-900 support, consistent decreases in both microporous and mesoporous surface area and pore volume with increasing Ru loading were observed (Table 1), indicating the successiful dispersion of metal NPs in both types of pores. This is also supported by the pore size distribution profiles (Supporting Information, Fig. S1), which showed notable decrease in micropores along with narrowing of mesopore distribution.

The role of activating agent, namely $\mathrm{ZnCl}_{2}$, during activation of $\mathrm{MOC}$ is worthy for further exploration. During the process, the impregnated $\mathrm{ZnCl}_{2}$ tends to promote dehydration of the carbon substrate, leading to charring and aromatization along with the creation of porosities. It is anticipated that mobile liquid $\mathrm{ZnCl}_{2}(\mathrm{~m} . \mathrm{p} . \sim$ 

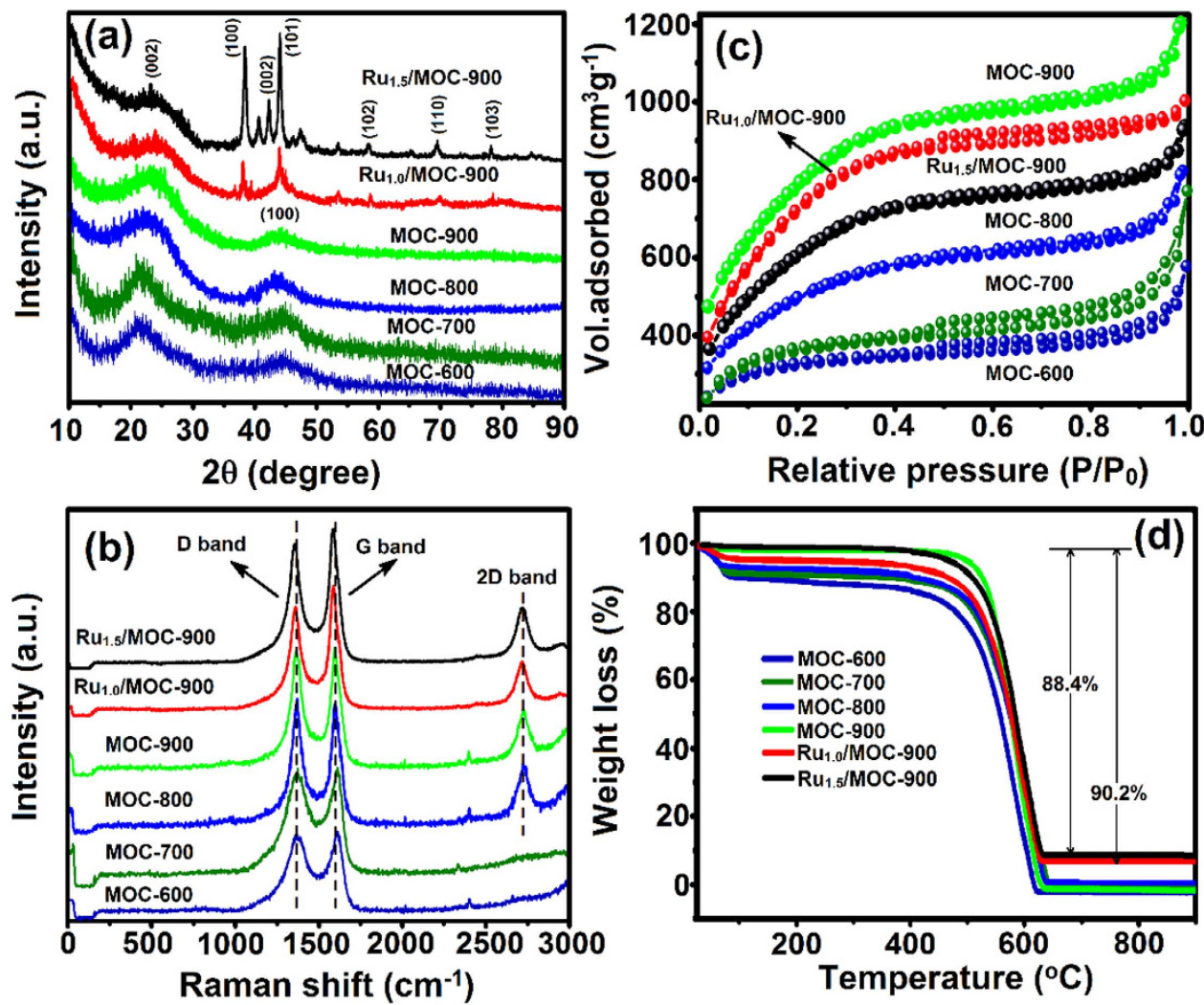

Figure 2. Physicochemical properties of various $M O C-\mathrm{T}_{\mathrm{c}}$ and $\mathrm{Ru}_{x} / \mathrm{MOC}-\mathrm{T}_{\mathrm{c}}$ materials. (a) XRD profiles. (b) Raman spectra. (c) $\mathrm{N}_{2}$ adsorption/desorption isotherms. (d) TGA curves.

\begin{tabular}{|c|c|c|c|c|c|c|c|c|c|c|}
\hline \multirow[b]{2}{*}{ Sample } & \multirow[b]{2}{*}{$\mathrm{T}_{\mathrm{c}}^{\mathrm{a}}$} & \multirow{2}{*}{$\begin{array}{c}\mathrm{Ru} \\
\text { loading }\end{array}$} & \multirow[b]{2}{*}{$M_{\mathrm{p}}^{\mathrm{c}}$} & \multicolumn{2}{|c|}{ Surface area $^{\mathrm{d}}$} & \multicolumn{3}{|c|}{ Pore volume $^{e}$} & \multirow[b]{2}{*}{$D_{\mathrm{p}}^{\mathrm{f}}$} & \multirow[b]{2}{*}{$I_{\mathrm{G}} / I_{\mathrm{D}}^{\mathrm{g}}$} \\
\hline & & & & $S_{\text {tot }}$ & $S_{\text {micro }}$ & $V_{\text {tot }}$ & $V_{\text {micro }}$ & $V_{\text {meso }}$ & & \\
\hline MOC-600 & 600 & - & - & 718 & 286 & 0.98 & 0.20 & 0.78 & 3.7 & 0.97 \\
\hline MOC-700 & 700 & - & - & 1384 & 456 & 1.02 & 0.30 & 0.72 & 3.8 & 0.98 \\
\hline MOC-800 & 800 & - & - & 1924 & 480 & 1.33 & 0.39 & 0.94 & 3.9 & 0.99 \\
\hline MOC-900 & 900 & - & - & 2522 & 576 & 1.78 & 0.46 & 1.33 & 4.3 & 1.21 \\
\hline $\mathrm{Ru}_{1.0} / \mathrm{MOC}-900$ & 900 & 1.0 & 2.8 & 2473 & 506 & 1.69 & 0.37 & 1.32 & 4.1 & 1.20 \\
\hline $\mathrm{Ru}_{1.5} / \mathrm{MOC}-900$ & 900 & 1.5 & 3.1 & 2015 & 439 & 1.48 & 0.29 & 1.19 & 3.9 & 1.21 \\
\hline
\end{tabular}

Table 1. Textural properties of various as-prepared MOC and Ru/MOC samples. (a) Carbonization temperature in ${ }^{\circ} \mathrm{C}$. (b) Ru loading in wt\% deduced from EDX and TGA results. (c) RuNP size in nm determined by FE-TEM analysis. (d) Brunauer-Emmet-Teller (BET) surface areas in unit of $\mathrm{m}^{2} \mathrm{~g}^{-1} ; S_{\text {tot }}$ and $S_{\text {micro }}$ denotes total and microporous surface area, respectively; $S_{\text {micro }}$ determined by t-plot analysis. (e) Total pore volume in $\mathrm{cm}^{3} \mathrm{~g}^{-1}$ calculated at $\mathrm{P} / \mathrm{P}_{0}=0.99$ of the $\mathrm{N} 2$ adsorption/desorption isotherm; $V_{\text {tot }}, V_{\text {micro }}$, and $V_{\text {meso }}$ represents total, microporous, and mesoporous pore volume, respectively, $V_{\text {meso }}=V_{\text {tot }}-V_{\text {micro. }}$ (f) Average pore size determined by non-local DFT calculations. (g) G to D band intensity ratio obtained from Raman data.

$283^{\circ} \mathrm{C}$ ) should be formed during the initial stage of the activation. Further increasing the activation temperature beyond $750^{\circ} \mathrm{C}$ (b.p. of $\mathrm{ZnCl}_{2} \mathrm{ca} .730^{\circ} \mathrm{C}$ ), strong interactions between carbon atoms and $\mathrm{Zn}$ species, which result in considerable collapses between the carbon interlayers to create pores in the matrix, as illustrated in Fig. $3^{73}$. It has been shown that the generation of micro- and mesoporosities (Table 1) is provoked by the elimination of hydrogen and oxygen atoms from the carbon substrate by $\mathrm{ZnCl}_{2}$, leading to the formation of water rather than oxygenated organic species ${ }^{74}$. The amount of activating agent, activation temperature, and subsequent washing by $\mathrm{HCl}$ were all found to have profound effect on the evolution of porosity within the MOC. At a fixed activation temperature, a gradual increase in BET surface area $\left(S_{\text {tot }}\right)$ of the as-synthesized MOC with increasing dosage of $\mathrm{ZnCl}_{2}$ was observed (Supporting Information, Fig. S2). For examples, at a low carbonization temperature $\left(600^{\circ} \mathrm{C}\right)$, the MOC prepared in absence of $\mathrm{ZnCl}_{2}$ exhibited a rather low $S_{\text {tot }}=50.6 \mathrm{~m}^{2} \mathrm{~g}^{-1}$. On the other hand, the surface area of MOC increased from ca. 210 to $718 \mathrm{~m}^{2} \mathrm{~g}^{-1}$ when prepared in the presence of 0.5 and $2.0 \mathrm{~g}$ of the activating agent (Supporting Information, Fig. S3). A more pronounced effect was found for activation temperature, for example, upon increasing the temperature from 600 to $900^{\circ} \mathrm{C}$ while in presence of a fixed amount of 


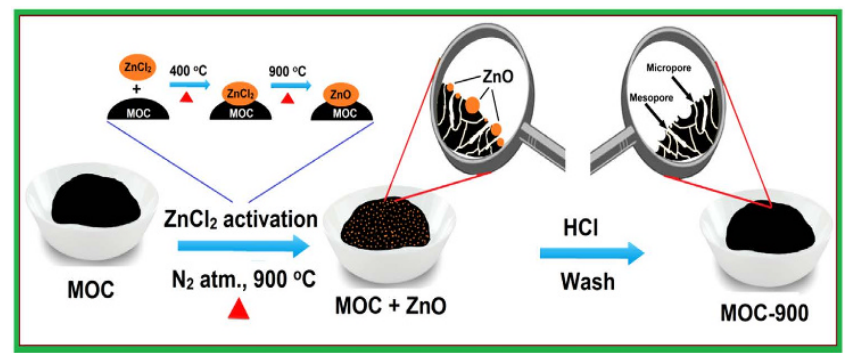

Figure 3. Schematic of the pore formation during activation of $\mathrm{MOC}$ at $900^{\circ} \mathrm{C}$ in the presence of $\mathrm{ZnCl}_{2}$ as activating agent.
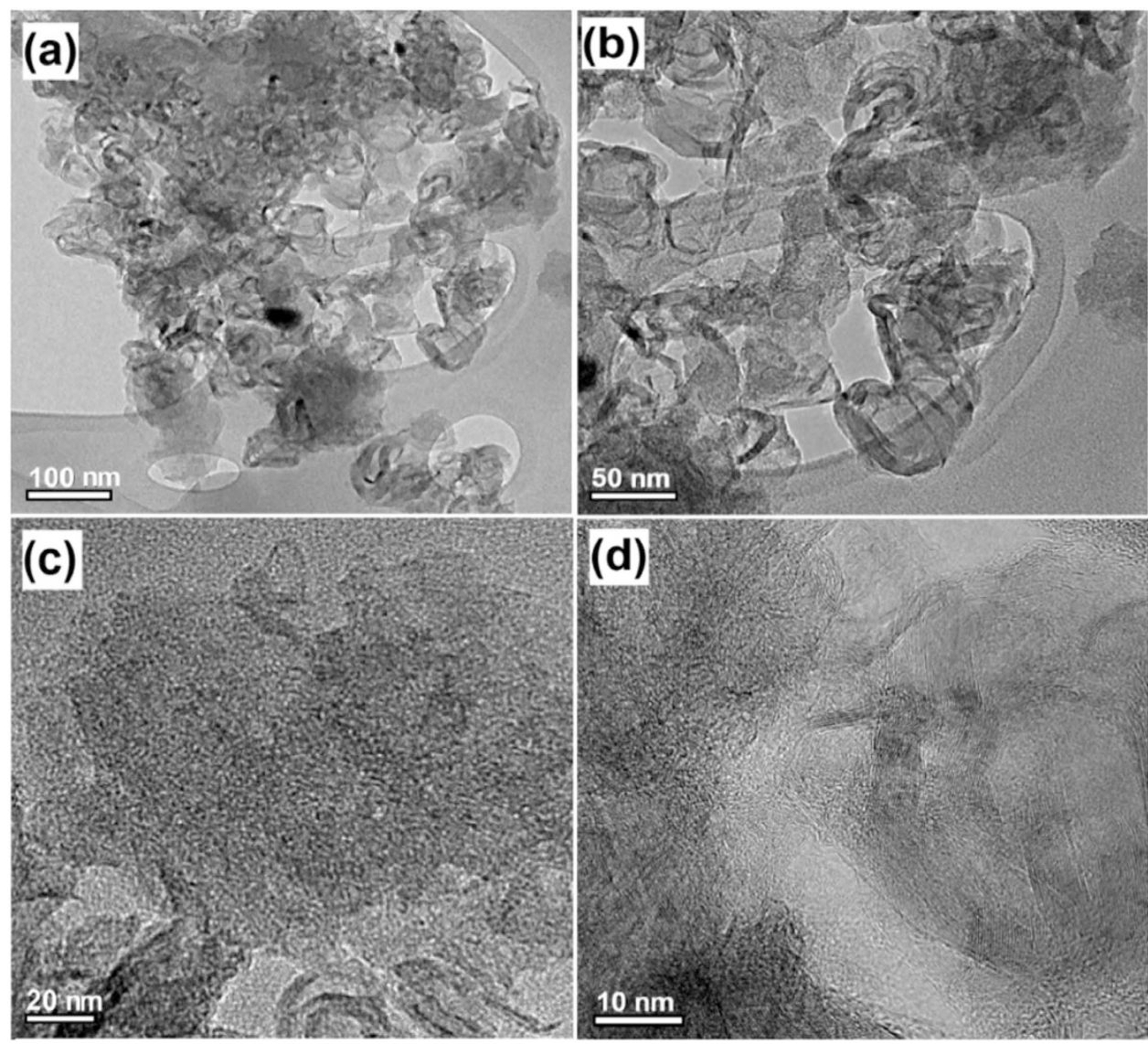

Figure 4. FE-TEM image of the MOC-900 at different magnifications. Scale bars: (a) 100, (b) $50 \mathrm{~nm}$, (c) 20, and (d) $10 \mathrm{~nm}$.

$\mathrm{ZnCl}_{2}(2.0 \mathrm{~g})$, the surface area of the resulting MOC increased drastically from 718 to $2522 \mathrm{~m}^{2} \mathrm{~g}^{-1}$. These results are consistent with earlier literature reports $\mathrm{s}^{75,76}$.

The TGA profiles of various MOC and Ru/MOC nanocomposites are displayed in Fig. 2d, their corresponding DTA curves are shown in Fig. S4 of the Supporting Information. Aside from the slight weight-loss below $150^{\circ} \mathrm{C}$ due to desorption of physisorbed water, all samples also showed a strong weight-loss at $\mathrm{ca} .620^{\circ} \mathrm{C}$, which should be associated with combustion of the MOC material ${ }^{77}$. The nearly complete weight-loss observed for the as-syntheized MOC- $\mathrm{T}_{c}\left(\mathrm{~T}_{\mathrm{c}}=600-900^{\circ} \mathrm{C}\right)$, indicating a complete oxidation of MOC by combustion and that nearly no trace of other ingredients (e.g., $\mathrm{Zn}$ species) were present in the PAC materials ${ }^{78}$. By comparison, while the Ru-loaded MOCs also exhibited two distinct weight-loss peaks at 50-150 and $400-620^{\circ} \mathrm{C}$, respectively, a residual weight-loss of $c a .9 .8$ and $11.6 \mathrm{wt} \%$ was observed for the $\mathrm{Ru}_{1.0} / \mathrm{MOC}-900$ and $\mathrm{Ru}_{1.5} / \mathrm{MOC}-900$, respectively, indicating the anticipated presence of remanent rutheniumn oxides.

The morphology and structural properties of the as-syntheiszed and Ru-loaded MOCs are examined by using FE-SEM/TEM, as shown in Figs 4 and 5. The as-prepared MOCs clearly possess abundant porosities, which tend to increase with increasing carbonization temperature, as illustrated in the magnified SEM and TEM images (see Supporting Information, Figs. S5 and S6) ${ }^{79}$. This can be seen by the TEM images of MOC- 900 sample taken at 

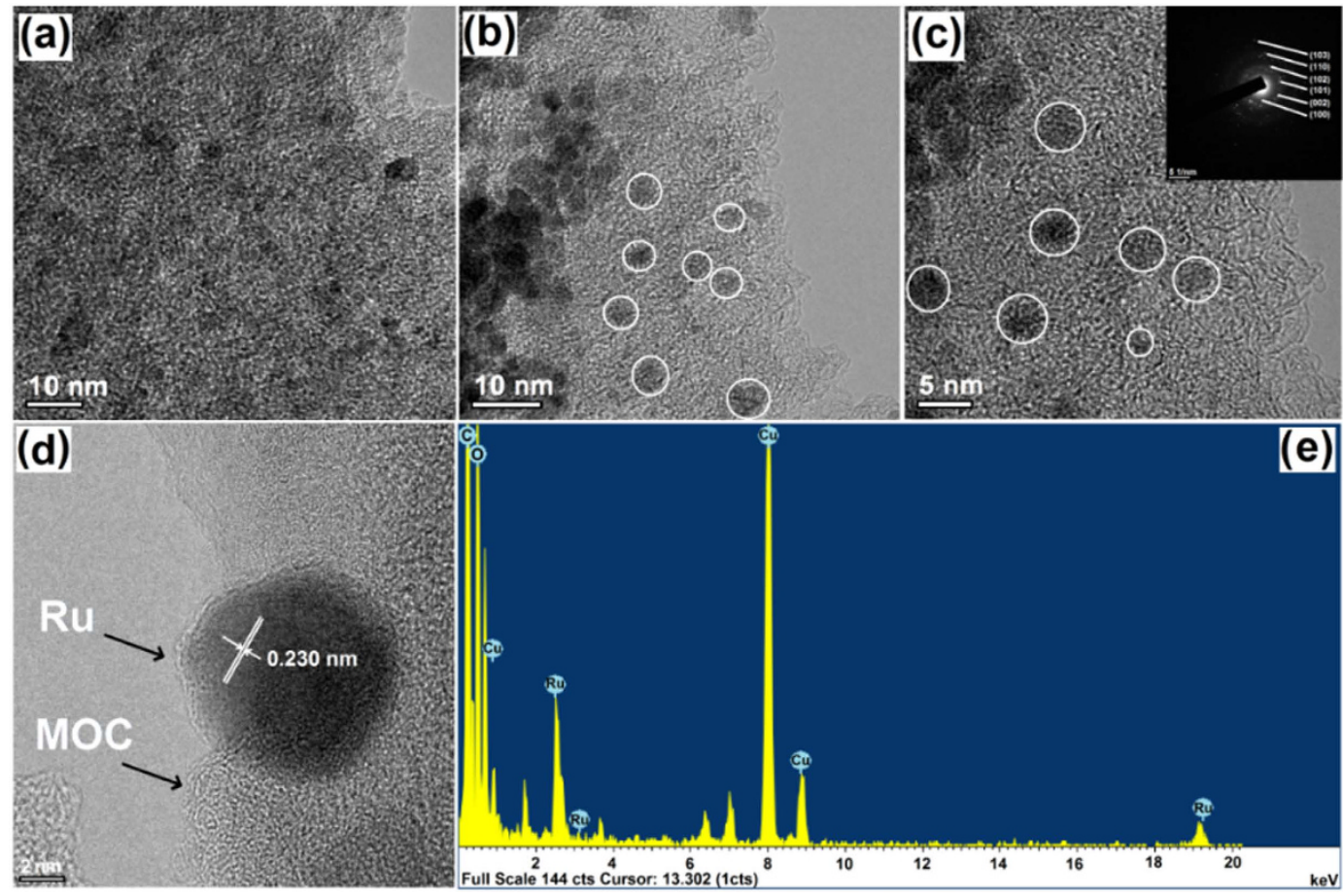

Figure 5. (a-d) FE-TEM images and (e) EDX profiles of Ru-loaded MOCs. (a) $\mathrm{Ru}_{1.5} / \mathrm{MOC}-900$ and (b-d) $\mathrm{Ru}_{1.0}$ /MOC-900 nanocomposites; the white circiles identify the presence of RuNPs. Inset in (c) shows the corresponding SAED pattern of RuNPs. (e) EDX profile of the $\mathrm{Ru}_{1.0} / \mathrm{MOC}-900$ sample.

different magnifications (Fig. 4), which clearly indicate the presences of interconnected micro- and mesopores with a curl-like morphology. For the MOC-900, a rather board distribution of mesopore sizes in the range of $c a$. $5-20 \mathrm{~nm}$ on the surfaces of the curl-like MOCs may be inferred.

Moreover, the dispersion of RuNPs on the surfaces of MOC-900 may be clearly observed for both Ru-loaded samples, as shown in Fig. 5. Further analysis indicate that the RuNPs has an average particle size of ca. $3 \mathrm{~nm}$ for both $\mathrm{Ru}_{1.5}$ /MOC-900 and $\mathrm{Ru}_{1.0}$ /MOC-900 nanocomposites, as illustrated in Fig. S7 of the Supproting Information. For the latter, analysis based on selected area electron diffraction (SAED) pattern (Inset, Fig. 5c) revealed the presences of (100), (002), (101), (102), (110), and (103) reflections corresponding to crystalline hcp structure of Ru metal. Based on the FE-TEM image of a single Ru metal NP (Fig. 5d), a lattice spacing of $0.230 \mathrm{~nm}$ was determined, in excellent agreement with the value derived from the XRD data of the (002) lattice plane (Fig. 2a). Moreover, analysis of the energy-dispersive X-ray (EDX) result (Fig. 5e) indicates the existences of various signals corresponding to $\mathrm{C} \mathrm{K} \alpha(0.2 \mathrm{keV}), \mathrm{Cu} \mathrm{L} \alpha, \beta(0.9 \mathrm{keV}), \mathrm{Cu} \mathrm{K} \alpha(8.0 \mathrm{keV}), \mathrm{Cu} \mathrm{K} \beta(8.9 \mathrm{keV}), \mathrm{Ru}$ $\mathrm{L} \alpha, \beta(2.6 \mathrm{keV}), \mathrm{Ru} \mathrm{L} \gamma(3.2 \mathrm{keV})$, and $\mathrm{Ru} \mathrm{K} \alpha(19.2 \mathrm{keV})$, respectively. The $\mathrm{Cu}$ signals arise from diffuse scattering of the $\mathrm{Cu}$ grid support ${ }^{80}$. The above results confirm a complete thermal reduction of Ru(acac $)_{3}$ to RuNPs, which are uniformly dispersed over the structural framework of the MOC support.

The surface properties of the MOC- 900 sample and Ru/MOC composites were further examined by X-ray photoelectron spectroscopy (XPS), as shown in Fig. 6. The XPS survey spectrum of the as-prepared MOC-900 (Fig. 6a) exhibits the anticipated C 1s $(282-290 \mathrm{eV})$ and $\mathrm{O} 1 \mathrm{~s}(530-535 \mathrm{eV})$ signals. The spectrum near the C $1 \mathrm{~s}$ and $\mathrm{O} 1 \mathrm{~s}$ regions, which are displayed in Fig. 6d,e, respectively, may further be deconvoluted to identify $\mathrm{C}-\mathrm{C}$ $(284.8 \mathrm{eV}), \mathrm{C}-\mathrm{O}(286.0 \mathrm{eV})$, and $\mathrm{C}=\mathrm{O}(289.2 \mathrm{eV})$ functional groups as well as the corresponding oxygen states of $\mathrm{C}=\mathrm{O}(521.8 \mathrm{eV})$ and $\mathrm{C}-\mathrm{O}(533.1 \mathrm{eV})$. For the $\mathrm{Ru}_{1.0} / \mathrm{MOC}-900$ and $\mathrm{Ru}_{1.5} / \mathrm{MOC}-900$ nanocomposites, additional overlapping peaks at binding energy of 284.3 and $280.7 \mathrm{eV}$ may be ascribed to the charistic peak of $\mathrm{Ru} 3 \mathrm{~d}^{3 / 2}$ and $\mathrm{Ru} 3 \mathrm{~d}^{5 / 281}$, further confirming the formation of metallic $\mathrm{Ru}^{0}$ by the chemical reduction.

Electrochemical Behavior of Ru/MOC-900 Electrodes. The electrochemical properties of the MOC900, $\mathrm{Ru}_{1.0} /$ MOC- 900 , and $\mathrm{Ru}_{1.5} /$ MOC-900 electrode materials were assessed by cyclic voltammetry (CV) and galvanostatic charge-discharge (GCD) method. The CV curves observed for various Ru/MOC-based electrodes in $1.0 \mathrm{M} \mathrm{H}_{2} \mathrm{SO}_{4}$ aqueous electrolyte solution are depicted in Fig. 7a, which all exhibited the typical rectangular shape electri double-layer capacitor (EDLC) behavior. Nonetheless, compared to the Ru/MOC electrode, the metal-free MOC-900 electrode showed only weak capacitive behavior. Among the three MOC-based electrodes examined, the $\mathrm{Ru}_{1.0} / \mathrm{MOC}-900$ electrode was found to exhibit an excellent pseudocapacitive redox property in the potential ranges of $0.4-0.6 \mathrm{~V}$. As shown earlier, the RuNPs embedded in the Ru/OMC-900 are highly dispersed in the carbon support, leading to a notable decrease in total surface area and pore volume with increasing metal loading (Table 1). As such, the inferior capacitive performance observed for the $\mathrm{Ru}_{1.5} / \mathrm{OMC}-900$ electrode compared to its counterpart with lower Ru loading (1.0 wt\%) may be attributed to hindrance in electron transport and ion diffusion 


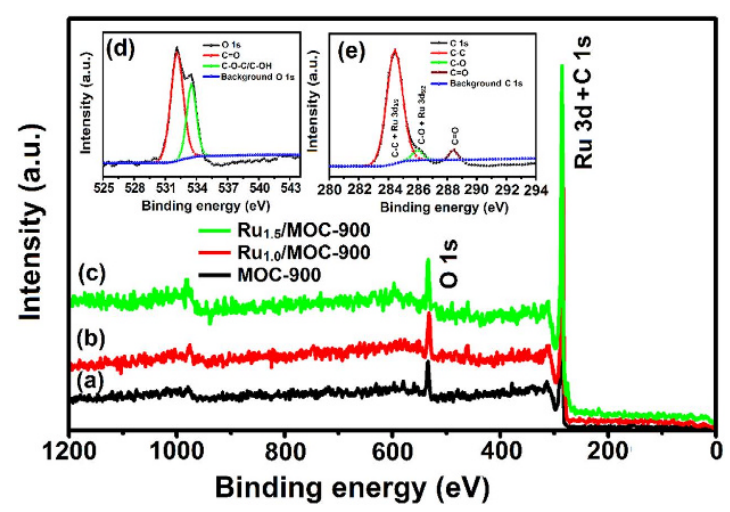

Figure 6. XPS spectra of various samples: (a) as-prepared MOC-900, (b) $\mathrm{Ru}_{1.0} / \mathrm{MOC}-900$, and (c) $\mathrm{Ru}_{1.5} / \mathrm{MOC}-900$ and their corresponding (d) C1s and (e) O1s spectrum.
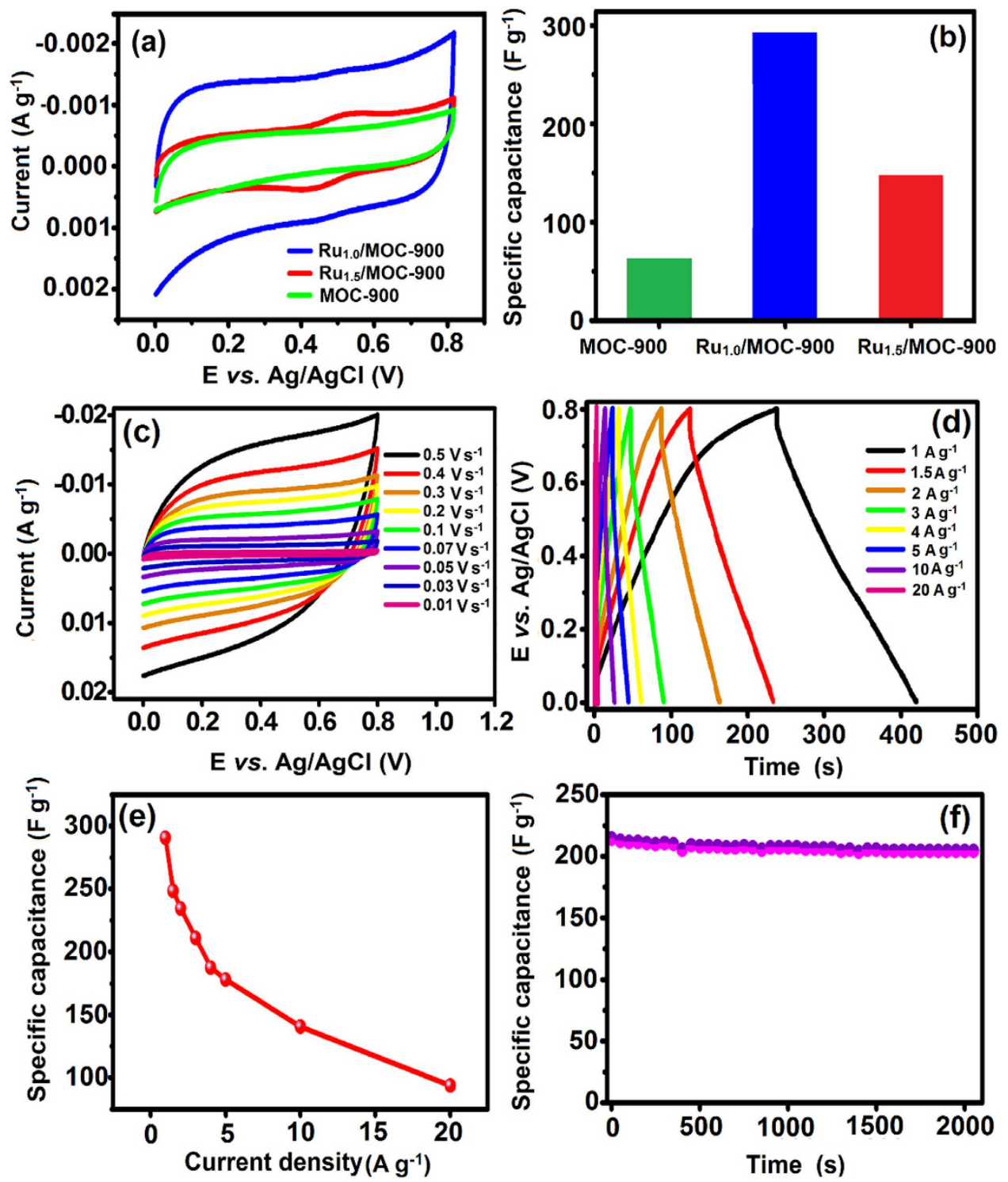

Figure 7. Electrochemical performances of assorted MOC-based electrodes . (a) CV curves recorded in $1.0 \mathrm{M} \mathrm{H}_{2} \mathrm{SO}_{4}$ aqueous electrolyte at a scan rate of $10 \mathrm{mV} \mathrm{s}^{-1}$. (b) Corrsponding specific capacitances observed for various electrodes. (c) CV curves recorded at different scan rates $\left(10-500 \mathrm{mV} \mathrm{s}^{-1}\right)$. (d) GCD curves at different current densities (1-20 $\left.\mathrm{A} \mathrm{g}^{-1}\right)$. (e) Variations of specific capacitance with current density. (f) Cyclic stability test at a constant current density of $4 \mathrm{~A} \mathrm{~g}^{-1}$. 


\begin{tabular}{|l|c|c|c|c|c|}
\hline Biomass feedstock & $\boldsymbol{S}_{\text {BET }}{ }^{\mathbf{a}}$ & Precursor/ZnCl $_{2}^{\mathbf{b}}$ & $\mathbf{C}^{\mathbf{c}}$ & Electrolyte & Reference \\
\hline Sugar cane bagasses & 1000 & $1: 1.75$ & 300 & $1 \mathrm{M} \mathrm{H}_{2} \mathrm{SO}_{4}$ & 23 \\
\hline Banana fibers & 1097 & $1: 5$ & 296 & $1 \mathrm{M} \mathrm{Na}_{2} \mathrm{SO}_{4}$ & 28 \\
\hline Coffee beans & 1019 & $1: 1$ & 368 & $1 \mathrm{M} \mathrm{H}_{2} \mathrm{SO}_{4}$ & 45 \\
\hline Coffee shells & 842 & $1: 20$ & 150 & $6 \mathrm{M} \mathrm{KOH}$ & 46 \\
\hline Camellia Oleifera fruit shells & 1935 & $1: 4$ & 374 & $1 \mathrm{M} \mathrm{H}_{2} \mathrm{SO}_{4}$ & 47 \\
\hline Walnut shells & 1073 & $2 \mathrm{M} \mathrm{ZnCl}$ & 117 & $6 \mathrm{M} \mathrm{KOH}$ & 48 \\
\hline Fermented rice & 2106 & - & 219 & $0.1 \mathrm{M} \mathrm{KOH}$ & 49 \\
\hline Potato wastes & 1052 & $1: 2$ & 255 & $2 \mathrm{M} \mathrm{KOH}$ & 50 \\
\hline Coconut shells & 2440 & $1: 3$ & 246 & $0.5 \mathrm{M} \mathrm{H}_{2} \mathrm{SO}_{4}$ & 51 \\
\hline Waste filter paper & 2170 & $1: 4$ & 302 & $6 \mathrm{M} \mathrm{KOH}$ & 52 \\
\hline Moringa Oleifera fruit shells & 2473 & $1: 1$ & 291 & $1 \mathrm{M} \mathrm{H}_{2} \mathrm{SO}_{4}$ & This work \\
\hline
\end{tabular}

Table 2. Comparisons of textual and capacitive properties of various biomass-derived activated carbons. (a) BET surface area in $\mathrm{m}^{2} \mathrm{~g}^{-1}$. (b) Ratio of carbon precursor to $\mathrm{ZnCl}_{2}$. (c) Capacitance in $\mathrm{F} \mathrm{g}^{-1}$.

by the embedded metal. Overall, a maximum capacitance of $291 \mathrm{~F} \mathrm{~g}^{-1}$ was observed for the $\mathrm{Ru}_{1.0} / \mathrm{MOC}-900$ electrode comparing to that of its MOC-900 and $\mathrm{Ru}_{1.5} / \mathrm{MOC}-900$ counterparts, as shown in Fig. $7 \mathrm{~b}$.

To further assess the characteristics of the $\mathrm{Ru}_{1.0} / \mathrm{MOC}-900$ nanocomposite for its practical application as electrode material for supercapacitors, we conducted further electrochemical studies. As can be seen from the $\mathrm{CV}$ curves recorded at vaired scan rates from 10 to $500 \mathrm{mV} \mathrm{s}^{-1}$ shown in Fig. $7 \mathrm{c}$, all curves retained the rectangular-shape even at high scan rates, which indicates that the $\mathrm{Ru}_{1.0} / \mathrm{MOC}-900$ electrode indeed exhibits excellent capacitive property with good electrical conductivity ${ }^{82}$. Moreover, based on the GCD curves measured for the $\mathrm{Ru}_{1.0} /$ MOC-900 electrode at different current densities from 1 to $20 \mathrm{~A} \mathrm{~g}^{-1}$ (Fig. $7 \mathrm{~d}$ ), a gradual decrease in the corresponding specific capacitance with current densitiy from 291 to $94 \mathrm{~F} \mathrm{~g}^{-1}$ was observed (Fig. 7e). The durability of the $\mathrm{Ru} / \mathrm{MOC}$ electrode was also evaluated. As shown in Fig. $7 \mathrm{f}$, the $\mathrm{Ru}_{1.0} / \mathrm{MOC}-900$ electrode retained over $90 \%$ of its initial capacitance after more than 2000 charge-discharge cycles when recorded at a constant current density of $4 \mathrm{~A} \mathrm{~g}^{-1}$, revealing an extraordinary stability and durability. For comparision, the textural and capacitive properties of other activated carbon (AC)-electrodes derived from various biomass feedstock are depicted in Table $2^{23,24,28,45-52}$. It is indicative that the Ru/MOC electrode exhibits comparable capacitive performance even with a modest Ru loading of only $1 \mathrm{wt} \%$. The MOC material derived from Moringa Oleifera fruit shells clearly has the advantage of achieving a high surface area $\left(2473 \mathrm{~m}^{2} \mathrm{~g}^{-1}\right)$, this together with the use of a activating agent $\left(\mathrm{ZnCl}_{2}\right)$ and thermal reduction procedures help to facilitate dispersion of the metal $(\mathrm{Ru}) \mathrm{NPs}$ and formation of micro- and mesoporosities favorable for electron transport and ion diffusion in the MOC matrix, hence, the superior electrochemical performances and excellent stability and durability well-suited for application of high-performance supercapactiors.

To enhance the energy densities, the fabricated symmetric cell supercapacitor was operated at various potential ranges (Fig. 8a) and scan rates (Fig. 8b). Accordingly, the corresponding calculated specific capacitance of 36.2 to $11.5 \mathrm{~F} \mathrm{~g}^{-1}$ was obtained using the known total mass of the electrode. The increase in capacitive current with increasing scan rate may be ascribed due to intercalation and deintercalation of ions ${ }^{24}$. Likewise, the GCD curves recorded at different potential ranges and current densities are displayed in Fig. 8c,d, respectively, which corresponds to a maximum specific capacitance and current density of $31.6 \mathrm{~F} \mathrm{~g}^{-1}$ and $0.25 \mathrm{~A} \mathrm{~g}^{-1}$, respectively. The specific capacitance so obtained is comparable to earlier literature reports ${ }^{83}$.

The long-term stability of the symmetric cell supercapacitor was also tested upto 1000 charge-discharge cycles at a current density of $0.75 \mathrm{~A} \mathrm{~g}^{-1}$. As a result, $c a .97 \%$ of its initial capacitance was retained after 1000 cycles (Fig. 8e). Finally, the correlation between power and energy densities of such solid-state device was also investigated; a maximum energy density of $6.3 \mathrm{Wh} \mathrm{kg}^{-1}$ at a power density of $250 \mathrm{~W} \mathrm{~kg}^{-1}$ was achieved (Fig. 8e).

In summary, a series of novel porous activated carbon materials derived from Moringa Oleifera fruit shells via a facile annealing and chemical activation process using $\mathrm{ZnCl}_{2}$ as activating agent have been developed and exploited as electrode support for electrochemical energy storage. When incorporated with RuNPs by thermal reduction using ruthenium(III) acetylacetonate as the metal precursor, the Ru/MOC materials so fabricated exhibits not only superior textural properties but also excellent capacitive properties with extraordinarly stability and durability. A maximum specific capacitance of $291 \mathrm{~F} \mathrm{~g}^{-1}$ was achieved for the $\mathrm{Ru}_{1.0} / \mathrm{MOC}-900^{\circ} \mathrm{C}$ electrode (Ru loading $1.0 \mathrm{wt} \%$; activation temperature $900^{\circ} \mathrm{C}$ ) at a current density of $1 \mathrm{~A} \mathrm{~g}^{-1}$. The results obtained from a cyclic charge-discharge test showed that the same electrode retained more than $90 \%$ of it original capacitance after 2000 consecutive test cycles at $4 \mathrm{~A} \mathrm{~g}^{-1}$. We believe that these MOC materials, which possess desirable textural properties, co-exsisting micro- and mesoporosities, and good electrical conductivities should render prospective applications in high-performance energy storage devices, biosensors, and catalysis, especially when combining with different metal oxides or conductive polymers as porous composites.

\section{Experimental}

Materials. Research grade ruthenium(III) acetylacetonate ( $\mathrm{Ru}(\mathrm{acac})_{3}, 96 \%$; $\left.\mathrm{Acros}\right)$, zinc chloride $\left(\mathrm{ZnCl}_{2}\right.$; Sigma-Aldrich), potassium hydroxide (KOH; Sigma-Aldrich)) and poly vinyl alcohol (PVA; Shimakyu) were purchased commercially and used without further purification. Drumstick fruit shells (Moringa Oleifera; Family: Moringaceae) were collected from Theni district, Tamil Nadu, India. All solutions were prepared using doubly distilled water. 

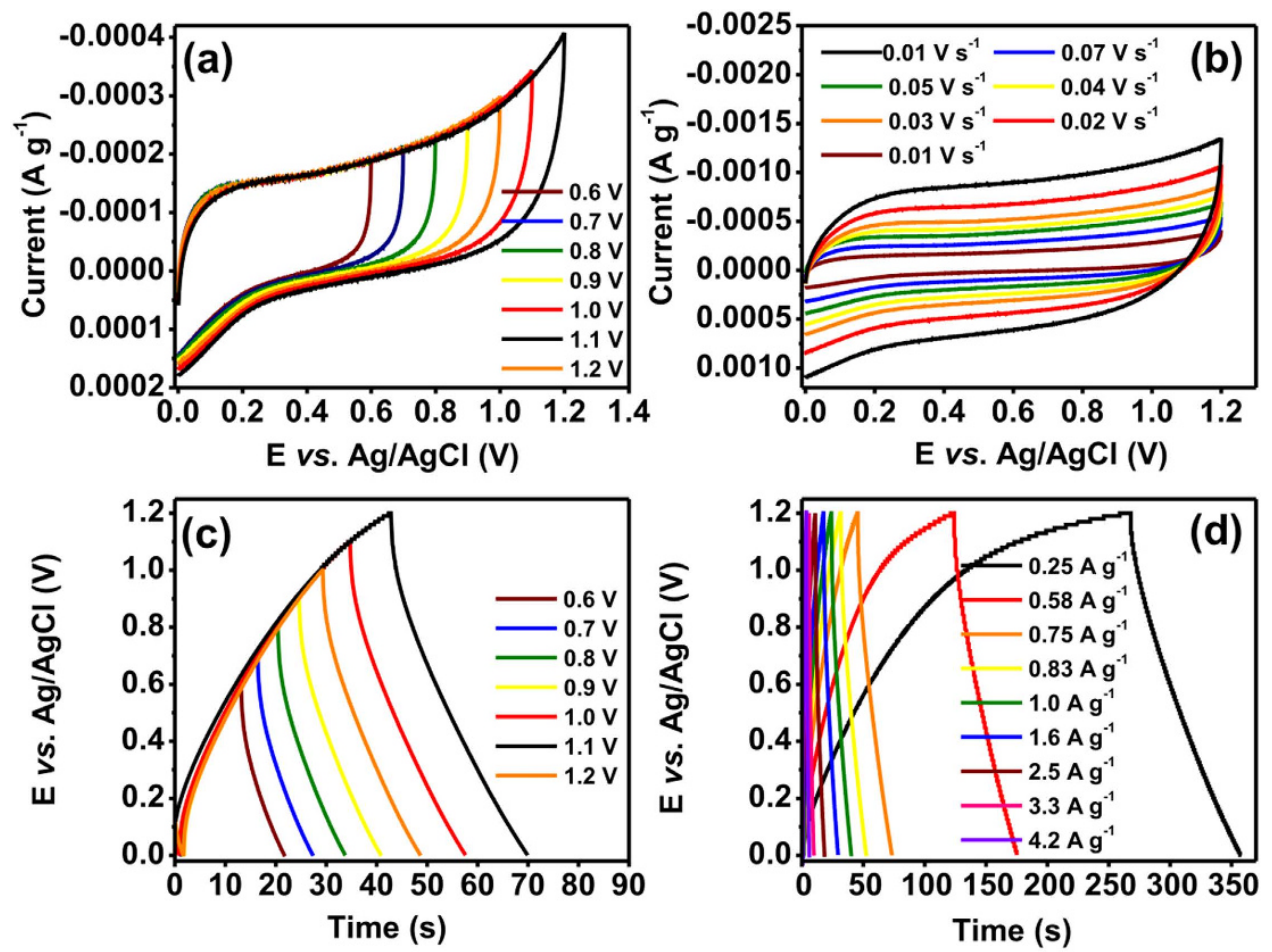

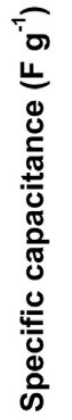
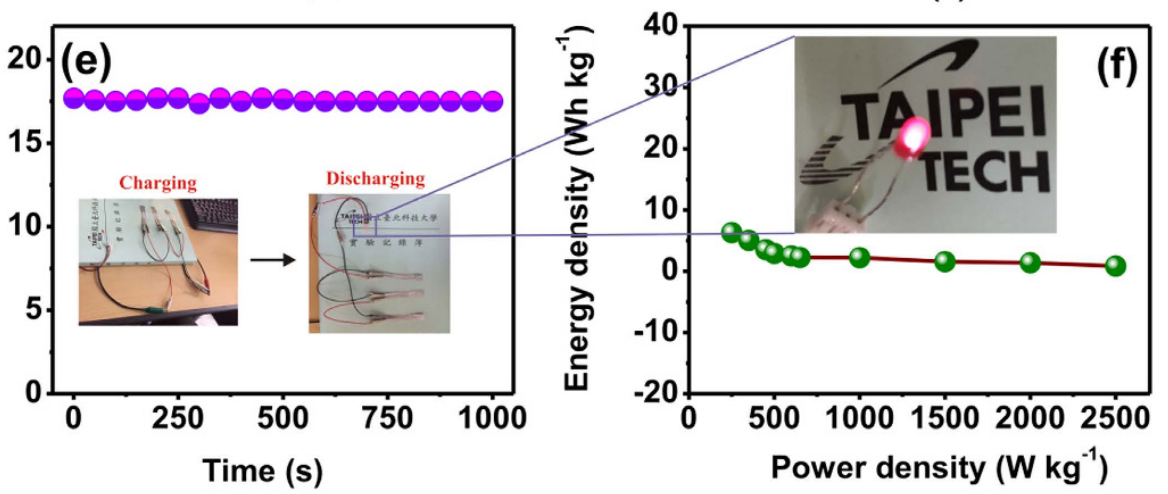

Figure 8. Performance assessments of the symmetric cell supercapacitor fabricated based on the $\mathbf{R u}_{1.0}$ /MOC-900 composite. CV curves recorded with varied (a) potential ranges and (b) scan rates. Corresponding GCD curves measured at varied (c) potential ranges and (d) current densities. (e) Cyclic stability test at a constant current density of $0.75 \mathrm{~A} \mathrm{~g}^{-1}$; insets: photographs of the as-prepared electrode during charge and discharge process. (f) Ragone plot of the solid-state device.

Characterization Methods. All powdered $\mathrm{x}$-ray diffraction (XRD) experiments were recorded on a PANalytical (X'Pert PRO) diffractometer using CuK $\alpha$ radiation $(\lambda=0.1541 \mathrm{~nm})$. Nitrogen adsorption/desorption isotherm measurements were carried out on a Quantachrome Autosorb-1 volumetric adsorption analyzer at $-196^{\circ} \mathrm{C}$. Prior to measurement, the sample was purged with flowing $\mathrm{N}_{2}$ at $150^{\circ} \mathrm{C}$ for at least $12 \mathrm{~h}$. The pore size distributions were derived from density functional theory (DFT) calculations. The morphology of the sample was studied by field-emission transmission electron microscopy (FE-TEM) at room temperature $\left(25^{\circ} \mathrm{C}\right)$ using an electron microscope (JEOL JEM-2100F) operating at $200 \mathrm{kV}$. Elemental compositions of various samples were carried out with an energy-dispersive x-ray (EDX) analyser; an accessory of the FE-TEM facility. X-ray photoelectron spectroscopy (XPS) measurements were performed using a ULVAC-PHI PHI 5000 VersaProb apparatus. Thermogravimetric analyses (TGA) were done on a Netzsch TG-209 instrument under air atmosphere. All Raman spectra were recorded on a Jobin Yvon T64000 spectrometer equipped with a charge coupled device (CCD) detector cooled with liquid nitrogen. The backscattering signal was collected with a microscope using an $\mathrm{Ar}^{+}$laser centered at $488 \mathrm{~nm}$ as the excitation source.

Synthesis of Activated Carbon (MOC). The Moringa Oleifera fruit shells were first air-dried and cut into pieces, then subjected to microwave irradiation (typically for $1-2 \mathrm{~h}$ ) to obtain the pyrolytic MO fruit shells (denoted as MOFS). Typically, the activation of the carbon precursor was carried out by impregnating $1.0 \mathrm{~g}$ of MOFS in aqueous solution of $\mathrm{ZnCl}_{2}(2.0 \mathrm{~g})$ under sonication, followed by an evaporation treatment at $80^{\circ} \mathrm{C}$. The dried MOFS $/ \mathrm{ZnCl}_{2}$ mixture was then heated at different temperatures $\left(600,700,800\right.$, and $\left.900^{\circ} \mathrm{C}\right)$ for $5 \mathrm{~h}$ under 
$\mathrm{N}_{2}$ atmosphere at a heating rate of $5 \mathrm{oC} \mathrm{min}{ }^{-1}$. Finally, the sample was washed with $2 \mathrm{M} \mathrm{HCl} \mathrm{solution}$ and washed with hot deionized water until reaching a $\mathrm{pH}=7$. The sample was then dried at $80^{\circ} \mathrm{C}$ in an air oven. The final as-synthesized carbon products so obtained are named as activated Moringa Oleifera carbons (MOCs) and the samples prepared at different cabonization temperature $\left(\mathrm{T}_{\mathrm{c}}\right.$; in $\left.{ }^{\circ} \mathrm{C}\right)$ are denoted as MOC- $\mathrm{T}_{\mathrm{c}}$.

Preparation of Ru/MOC nanocomposite. Typically, a known amount of activated carbon (MOC) was first impregnated in nitric acid $\left(\mathrm{HNO}_{3}\right)$ solution for $3 \mathrm{~h}$ at $80^{\circ} \mathrm{C}$ in an ultrasonic bath. The hydrophilic mixture was then filtrated and dried at room temperature. Then, $0.1 \mathrm{~g}$ of the treated powdered MOC-900 sample was impregnated into an ethanol solution $(3 \mathrm{~mL})$ containing desirable amount of $\mathrm{Ru}(\mathrm{acac})_{3}$ under continuous ultrasonication for $1 \mathrm{~h}$. Subsequently, the sample vacuum dried to remove the solvent, then subjected to microwave irradiation (at $200^{\circ} \mathrm{C}$ for $2 \mathrm{~h}$ ), followed by pyrolysis at high temperature $\left(900^{\circ} \mathrm{C}\right)$ under $\mathrm{N}_{2}$ atmosphere for $5 \mathrm{~h}$. The nanocomposites so prepared are denoted as $\mathrm{Ru}_{x} / \mathrm{MOC}-900$, where $x$ represents the Ru loading $(x=1.0$ or $1.5 \mathrm{wt} \%)$.

Fabrication of $\mathbf{R u}_{\mathbf{x}} / \mathrm{MOC}$ Electrodes. For supercapacitor applications, the $\mathrm{Ru} / \mathrm{MOC}$-electrodes were prepared by mixing Ru/MOC ( $85 \mathrm{wt} \%)$ and graphite $(15 \mathrm{wt} \%)$ with $0.4 \mathrm{~mL}$ of $\mathrm{N}$-methylpyrrolidone to form a homogeneous slurry. Then, $c a .15 \mu \mathrm{L}$ of the above slurry was coated on a stainless steel electrode with a dimension of about $1 \times 1 \mathrm{~cm}^{2}$ by means of the solution-casting method, followed by drying overnight at $60^{\circ} \mathrm{C}$. The mass loading of $\mathrm{Ru} / \mathrm{MOC}$ on the substrate was estimated to be $c a .1 .5 \mathrm{mg} \mathrm{cm}^{-2}$. For comparison purpose, separate MOC-electrodes (in absence of $\mathrm{Ru}$ ) were also prepared following the above procedures. For fabricating the symmetric supercapacitor cell, two $\mathrm{Ru} / \mathrm{MOC}$ electrodes were attached face to face by using $\mathrm{PVA} / \mathrm{H}_{2} \mathrm{SO}_{4}$ gel electrolyte as a separator.

Electrochemical Studies. Electrochemical properties of various MOC- 900 and $\mathrm{Ru}_{1.0} / \mathrm{MOC}-900$ electrodes were assessed by using a three-electrode system (in 1.0 M KOH aqueous electrolyte solution) consisting of the fabricated working electrode, $\mathrm{Ag} / \mathrm{AgCl}$ as the reference electrode, and a platinum $(\mathrm{Pt})$ wire as the counter electrode. All the cyclic votammetry (CV) and galvanostatic charge-discharge (GCD) experiments were performed on an electrochemical work station (CH Instrument; CHI627). Prior to each measurement, the cell was soaked in the aqueous electrolyte solution $\left(1 \mathrm{M} \mathrm{H}_{2} \mathrm{SO}_{4}\right)$ for a few hours. Typically, the $\mathrm{CV}$ profiles of the electrodes were recorded in the potential range of -1.0 to $0.0 \mathrm{~V}$. The specific capacitance of various electrodes were calculated according to equation reported elsewhere ${ }^{20,84}$.

\section{References}

1. Lee, J., Kim, J. \& Hyeon, T. Recent progress in the synthesis of porous carbon materials. Adv. Mater. 18, 2073-2094 (2006).

2. Hu, Z., Srinivasan, M. P. \& Ni, Y. Preparation of mesoporous high-surface-area activated carbon. Adv. Mater. 12, 62-65 (2000).

3. Vix-Guterl, C. et al. Electrochemical energy storage in ordered porous carbon materials. Carbon 43, 1293-1302 (2005).

4. Chen, Y. \& Liu, Y. Preparation of porous carbon with high dispersion of Ru nanoparticles by sol-gel method and its application in hydrogen storage. J. Mater. Chem. A 2, 9193-9199 (2014).

5. Roldán, L., Marco, Y. \& García-Bordejé, E. Function of the support and metal loading on catalytic carbon dioxide reduction using ruthenium nanoparticles supported on carbon nanofibers. Chem CatChem 7, 1347-1356 (2015).

6. Li, Y., Pan, C., Han, W., Chai, H. \& Liu, H. An efficient route for the preparation of activated carbon supported ruthenium catalysts with high performance for ammonia synthesis. Catal. Today 174, 97-105 (2011).

7. Veerakumar, P. et al. Highly stable and active palladium nanoparticles supported on porous carbon for practical catalytic applications. J. Mater. Chem. A. 2, 16015-16022 (2014).

8. Liu, S. H. et al. Controlled synthesis of highly dispersed platinum nanoparticles in ordered mesoporous carbons. Chem. Commun. 32, 3435-3437 (2006).

9. Liu, S. H. et al. Fabrication and characterization of well-dispersed and highly stable PtRu nanoparticles on carbon mesoporous material for applications in direct methanol fuel cell. Chem. Mater. 20, 1622-1628 (2008).

10. Liu, S. H., Chiang, C. C., Wu, M. T. \& Liu, S. B. Electrochemical activity and durability of platinum nanoparticles supported on ordered mesoporous carbons for oxygen reduction reaction. Inter. J. Hydrogen Energy 35, 8149-8154 (2010).

11. Liu, S. H. et al. Fabrication and electrocatalytic performance of highly stable and active platinum nanoparticles supported on nitrogen-doped ordered mesoporous carbons. J. Mater. Chem. 21, 12489-12496 (2011).

12. Hung, C. T. et al. Highly nitrogen-doped mesoscopic carbons as efficient metal-free electrocatalysts for oxygen reduction reactions. J. Mater. Chem. A 2, 20030-20037 (2014).

13. Veerakumar, P. et al. Porous carbon-modified electrodes as highly selective and sensitive sensors for detection of dopamine. Analyst 139, 4994-5000 (2014).

14. Veeramani, V., Madhu, R., Chen, S. M., Veerakumar, P. \& Liu, S. B. Heteroatom-enriched porous carbon/nickel oxide nanocomposites as enzyme-free highly sensitive sensors for detection of glucose. Sens. Actuators B 221, 1384-1390 (2015).

15. Veeramani, V. et al. Cajeput tree bark derived activated carbon for the practical electrochemical detection of vanillin. New J. Chem. 39, 9109-9115 (2015).

16. Cha, C., Shun, S. R., Annabi, M. R. \& Khademhosseini, A. Carbon-based nanomaterials: multifunctional materials for biomedical engineering. ACS Nano 7, 2891-2897 (2013).

17. Veerakumar, P. et al. Nickel nanoparticles decorated porous carbons for highly active catalytic reduction of organic dyes and sensitive detection of $\mathrm{Hg}(\mathrm{II})$ ions. ACS Appl. Mater. Interfaces 7, 24810-24821 (2015).

18. Madhu, R., Veeramani, V. \& Chen, S. M. Fabrication of a novel gold nanospheres/activated carbon nanocomposite for enhanced electrocatalytic activity toward the detection of toxic hydrazine in various water samples. Sens. Actuators B 204, 382-387 (2014).

19. Gao, Y. et al. Chemical activation of carbon nano-onions for high-rate supercapacitor electrodes. Carbon 51, 52-58 (2013).

20. Madhu, R., Veeramani, V., Chen, S. M., Veerakumar, P. \& Liu, S. B. Functional porous carbon/nickel oxide nanocomposites as binder-free electrodes for supercapacitors. Chem. Eur. J. 21, 8200-8206 (2015).

21. Wang, K. et al. Promising biomass-based activated carbons derived from willow catkins for high performance supercapacitors. Electrochimica Acta. 166, 1-11 (2015).

22. Wang, R. et al. Promising porous carbon derived from celtuce leaves with outstanding supercapacitance and $\mathrm{CO}_{2}$ capture performance. ACS Appl. Mater. Interfaces. 4, 5800-5806 (2012).

23. Rufford, T. E., Hulicova-Jurcakova, D., Khosta, K., Zhu, Z. \& Lu, G. Q. Microstructure and electrochemical double-layer capacitance of carbon electrodes prepared by zinc chloride activation of sugar cane bagasse. J. Power Sources 195, 912-918 (2010). 
24. Madhu, R., Sankar, K. V., Chen, S. M. \& Selvan, R. K. Eco-friendly synthesis of activated carbon from dead mango leaves for the ultrahigh sensitive detection of toxic heavy metal ions and energy storage applications. RSC Adv. 4, 1225-1233 (2014).

25. Li, J. \& Wu, Q. Water bamboo-derived porous carbons as electrode materials for supercapacitors. New J. Chem. 39, 3859-3864 (2015).

26. Li, Z. et al. A sheet-like porous carbon for high-rate supercapacitors produced by the carbonization of an eggplant. Carbon 92, 11-14 (2015).

27. Wu, X. et al. Biomass-derived sponge-like carbonaceous hydrogels and aerogels for supercapacitors. ACS Nano 7, 3589-3597 (2013).

28. Subramanian, V. et al. Supercapacitors from activated carbon derived from banana fibers. J. Phys. Chem. C 111, 7527-7531 (2007).

29. Senthilkumar, S. T., Kalai Selvan R., Melo, J. S. \& Sanjeeviraja, C. High performance solid-state electric double layer capacitor from redox mediated gel polymer electrolyte and renewable tamarind fruit shell derived porous carbon. ACS Appl. Mater. Interfaces 5, $10541-10550$ (2013).

30. Sun, L. et al. From coconut shell to porous graphene-like nanosheets for high-power supercapacitors. J. Mater. Chem. A 1, 6462-6470 (2013).

31. Gao, Y. et al. Porous carbon made from rice husk as electrode material for electrochemical double layer capacitor. Appl. Energy 153, 41-47 (2015)

32. Madhu, R. et al. Honeycomb-like porous carbon-cobalt oxide nanocomposite for high-performance enzymeless glucose sensor and supercapacitor applications. ACS Appl. Mater. Interfaces 7, 15812-15820 (2015).

33. Xiong, W. et al. Composite of macroporous carbon with honeycomb-like structure from mollusc shell and $\mathrm{NiCo}_{2} \mathrm{O}_{4}$ nanowires for high-performance supercapacitor. ACS Appl. Mater. Interfaces 6, 19416-19423 (2014).

34. Huang, J. et al. Hierarchical porous graphene carbon-based supercapacitors. Chem. Mater. 27, 2107-2113 (2015).

35. Leng, X., Zou, J., Xiong, X. \& He, H. Hydrothermal synthesis and pseudo capacitance behavior of a highly homogeneous dispersed graphene sheets/ruthenium oxide nanocomposite. RSC Adv. 4, 61596-61603 (2014).

36. Soin, N., Roy, S. S., Mitra, S. K., Thundai, T. \& McLaughlin, J. A. Nanocrystalline ruthenium oxide dispersed few layered graphene (FLG) nanoflakes as supercapacitor electrodes. J. Mater. Chem. 22, 14944-14950 (2012).

37. Sui, Z., Meng, Q., Zhang, X., Ma, R. \& Cao, B. Green synthesis of carbon nanotube-graphene hybrid aerogels and their use as versatile agents for water purification. J. Mater. Chem. 22, 8767-8771 (2012).

38. Wang, W. et al. Hydrous ruthenium oxide nanoparticles anchored to graphene and carbon nanotube hybrid foam for supercapacitors. Sci. Rep. 4, 44 (2014).

39. Lin, Y. S., Lee, K. Y., Chen, K. Y. \& Huang, Y. S. Superior capacitive characteristics of $\mathrm{RuO}_{2}$ nanorods grown on carbon nanotubes. Appl. Surf. Sci. 256, 1042-1045 (2009).

40. Kim, Y. T., Tadai, K. \& Mitani, T. Highly dispersed ruthenium oxide nanoparticles on carboxylated carbon nanotubes for supercapacitor electrode materials. J. Mater. Chem. 15, 4914-4921 (2005).

41. Ferrero, G. A., Sevilla, M. \& Fuertes, A. B. Mesoporous carbons synthesized by direct carbonization of citrate salts for use as highperformance capacitors. Carbon 88, 239-251 (2015).

42. Li, H., Wang, R. \& Cao, R. Physical and electrochemical characterization of hydrous ruthenium oxide/ordered mesoporous carbon composites as supercapacitor. Micropor. Mesopor. Mater. 111, 32-38 (2008).

43. Zhang, C. et al. Enhanced electrochemical performance of hydrous $\mathrm{RuO}_{2} /$ mesoporous carbon nanocomposites via nitrogen doping. ACS Appl. Mater. Interfaces 6, 9751-9759 (2014).

44. Porada, S. et al. Direct prediction of the desalination performance of porous carbon electrodes for capacitive deionization. Energy Environ. Sci. 6, 3700-3712 (2013).

45. Rufford, T. E., Hulicova-Jurcakova, D., Zhu, Z. \& Lu, G. Q. Nanoporous carbon electrode from waste coffee beans for high performance supercapacitors. Electrochem. Commun. 10, 1594-1597 (2008).

46. Jisha, M. R. et al. Electrochemical characterization of supercapacitor based on carbon derived from coffee shells. Mater. Chem. Phys. 115, 33-39 (2009).

47. Zhang, J., Gong, L., Sun, K., Jiang, J. \& Zhang, X. Preparation of activated carbon from waste Camellia Oleifera shell for supercapacitor application. J. Solid State Electrochem. 16, 2179-2186 (2012).

48. $\mathrm{Li}, \mathrm{Y} . \& \mathrm{Liu}, \mathrm{X}$. Activated carbon/ZnO composites prepared using hydrochars as intermediate and their electrochemical performance in supercapacitor. Mater. Chem. Phys. 148, 380-386 (2014).

49. Gao, S. et al. Large scale production of biomass-derived N-doped porous carbon spheres for oxygen reduction and supercapacitors. J. Mater. Chem. A 2, 3317-3324 (2014).

50. Ma, G. et al. Nitrogen-doped porous carbon derived from biomass waste for high-performance supercapacitor. Bioresource Technol. 197, 137-142 (2015).

51. Jain, A. et al. Mesoporous activated carbons with enhanced porosity by optimal hydrothermal pre-treatment of biomass for supercapacitor applications. Micropor. Mesopor. Mater. 218, 55-61 (2015).

52. Chang, B., Guo, Y., Li, Y. \& Yang, B. Hierarchical porous carbon derived from recycled waste filter paper as high-performance supercapacitor electrodes. RSC Adv. 5, 72019-72027 (2015).

53. Hayashi, J., Kazehaya, A., Muroyama, K. \& Watkinson, A. P. Preparation of activated carbon from lignin by chemical activation. Carbon 38, 1873-1878 (2000).

54. Lei, H., Wang, Y. \& Huo, J. Porous graphitic carbon materials prepared from cornstarch with the assistance of microwave irradiation. Micropor. Mesopor. Mater. 210, 39-45 (2015).

55. Olson, M. E. \& Carlquist, S. Stem and root anatomical correlations with life form diversity, ecology, and systematics in Moringa (Moringaceae). Bot. J. Linn. Soc. 135, 315-348 (2001)

56. Iqbal, S. \& Banger, M. I. Effect of season and production location on antioxidant activity of Moringa oleifera leaves grown in Pakistan. J. Food Compos. Anal. 19, 544-551 (2006).

57. Richter, N., Siddhuraju, P. \& Becker, K. Evaluation of nutritional quality of moringa (Moringa oleifera Lam.) leaves as an alternative protein source for Nile tilapia (Oreochromis niloticus L.). Aquaculture 217, 599-611 (2003).

58. Amaglo, N. K. et al. Profiling selected phytochemicals and nutrients in different tissues of the multipurpose tree Moringa oleifera L., grown in Ghana. Food Chem. 122, 1047-1054 (2010).

59. Guevara, A. P. at al. An antitumor promoter from Moringa oleifera Lam. Mutat. Res. Genet. Toxicol. Environ. Mutagen. 440, 181-188 (1999).

60. Costa-Lotufo, L. V. et al. Studies of the anticancer potential of plants used in Bangladeshi folk medicine. J. Ethnopharmacol. 99, 21-30 (2005)

61. Mahajan, S. G. \& Mehta, A. A. Immunosuppressive activity of ethanolic extract of seeds of Moringa oleifera Lam in experimental immune inflammation. J. Ethnopharmacol. 130, 183-186 (2010).

62. Warhurst, A. M., Mcconnachie, G. L. \& Pollard, S. J. T. Characterisation and applications of activated carbon produced from Moringa oleifera seed husks by single-step steam pyrolysis. Water Res. 31, 759-766 (1997).

63. Pollard, S. J. T., Thompson, F. E. \& Mcconnachie, G. L. Microporous carbons from Moringa oleifera husks for water purification in less developed countries. Water Res. 29, 337-347 (1995).

64. Akhtar, M., Hasany, S. M., Bhanger, M. I. \& Iqbal, S. Sorption potential of Moringa oleifera pods for the removal of organic pollutants from aqueous solutions. J. Hazard. Mater. 141, 546-556 (2007). 
65. Bhuptawat, H., Folkard, G. K. \& Chaudhari, S. Innovative physico-chemical treatment of wastewater incorporating Moringa oleifera seed coagulant. J. Hazard. Mater. 142, 477-482 (2007).

66. Warhurst, A. M., Fowler D., Mcconnachie, G. L. \& Pollard, S. J. T. Pore structure and adsorption characteristics of steam pyrolysis carbons from Moringa oleifera. Carbon 35, 1039-1045 (1997).

67. Kalavathy, M. H., Swaroop, G., Padmini, E. \& Miranda, L. R. A biosorbent for resorcinoladsorption-isotherm and kinetic studies. Carbon Lett. 10, 23-32 (2009).

68. Kim, T. W., Park, I. S. \& Ryoo, R. A. synthetic route to ordered mesoporous carbon materials with graphitic pore walls. Angew. Chem. Int. Ed. 42, 4375-4379 (2003).

69. Liu, J., Bai, P. \& Zhao, X. S. Ruthenium nanoparticles embedded in mesoporous carbon microfibers: preparation, characterization and catalytic properties in the hydrogenation of D-glucose. Phys. Chem. Chem. Phys. 13, 3758-3763 (2011).

70. Malard, L. M., Pimenta, M. A., Dresselhaus, G. \& Dresselhaus, M. S. Raman spectroscopy in graphene. Phys. Rep. 473, 51-87 (2009).

71. Dong, X. et al. Synthesis of graphene-carbon nanotube hybrid foam and its use as a novel three-dimensional electrode for electrochemical sensing. J. Mater. Chem. 22, 17044-17048 (2012).

72. Wang, Z. et al. Co-gelation synthesis of porous graphitic carbons with high surface area and their applications. Carbon 49, 161-169 (2011).

73. Caturla, F., Molina-Sabio, M. \& Rodriguez-Reinoso, F. Preparation of activated carbon by chemical activation with $\mathrm{ZnCl}_{2}$. Carbon 29, 999-1007 (1991).

74. Hu, Z. \& Vansant, E. F. A new composite adsorbent produced by chemical activation of elutrilithe with zinc chloride. J. Colloid. Inter. Sci. 176, 422-431 (1995).

75. Rodriguez-Reinoso, F. \& Molina-Sabio, M. Activated carbons from lignocellulosic materials by chemical and/or physical activation: an overview. Carbon 30, 1111-1118 (1992).

76. Hussein, M. Z., Zainal, Z., Ibrahim, R. \& Kheong, K. K. The preparation of activated carbons from chips of oil palm trunk catalysed by $\mathrm{ZnCl}_{2} / \mathrm{CO}_{2}$ : surface area and porosity studies. J. Chem. Tech. Biotechnol. 64, 35-40 (1995).

77. Mayes, R. T. et al. Hierarchical ordered mesoporous carbon from phloroglucinol-glyoxal and its application in capacitive deionization of brackish water. J. Mater. Chem. 20, 8674-8678 (2010).

78. Sun, L. et al. Magnetically separable porous graphitic carbon with large surface area as excellent adsorbents for metal ions and dye. J. Mater. Chem. 21, 7232-7239 (2011).

79. Qie, L. et al. Synthesis of functionalized 3D hierarchical porous carbon for high-performance supercapacitors. Energy Environ. Sci. 6, 2497-2504 (2013).

80. Veerakumar, P., Dhenadhayalan, N., Lin, K. C. \& Liu, S. B. Highly stable ruthenium nanoparticles on 3D mesoporous carbon: an excellent opportunity for reduction reactions. J. Mater. Chem. A, 3, 23448-23457 (2015).

81. Bavand, R., Yelon, A. \& Sacher, E. X-ray photoelectron spectroscopic and morphologic studies of Ru nanoparticles deposited onto highly oriented pyrolytic graphite. Appl. Surf. Sci. 355, 279-289 (2015).

82. Zhou, Z. et al. Amorphous $\mathrm{RuO}_{2}$ coated on carbon spheres as excellent electrode materials for supercapacitors. RSC Adv. 4, 6927-6932 (2014).

83. Du, X., Wang, C., Chen, M., Jiao, Y. \& Wang, J. Electrochemical performances of nanoparticle $\mathrm{Fe}_{3} \mathrm{O}_{4} /$ activated carbon supercapacitor using KOH electrolyte solution. J. Phys. Chem. C 113, 2643-2646 (2009).

84. Lu, X. et al. Facile synthesis of large-area manganese oxide nanorod arrays as a high-performance electrochemical supercapacitor. Energy Environ. Sci. 4, 2915-2921 (2011).

\section{Acknowledgements}

The financial supports of this work by the Ministry of Science and Technology (MOST), Taiwan (MOST-1042410-H-182-015 to BSL, MOST 104-2113-M-001-019 to SBL and NSC101-2113-M-027-001-MY3 to SMC) are gratefully acknowledged.

\section{Author Contributions}

P.V. and S.B.L. conceived the synthesis method and fabricated the Ru/MOC nanocomposite samples. They also performed physicochemical characterization of the materials and composed the manuscript. V.V. and R.M. performed the supercapacitor studies, analysed the data and wrote the manuscript. S.M.C., S.B.L. and B.S.L. supervised and finalized the project. All authors discussed the results and contributed to the final paper.

\section{Additional Information}

Supplementary information accompanies this paper at http://www.nature.com/srep

Competing financial interests: The authors declare no competing financial interests.

How to cite this article: Lou, B.-S. et al. Ruthenium nanoparticles decorated curl-like porous carbons for high performance supercapacitors. Sci. Rep. 6, 19949; doi: 10.1038/srep19949 (2016).

(c) (i) This work is licensed under a Creative Commons Attribution 4.0 International License. The images or other third party material in this article are included in the article's Creative Commons license, unless indicated otherwise in the credit line; if the material is not included under the Creative Commons license, users will need to obtain permission from the license holder to reproduce the material. To view a copy of this license, visit http://creativecommons.org/licenses/by/4.0/ 